\title{
Corneal ulceration, measles, and childhood blindness in Tanzania
}

\author{
ALLEN FOSTER' AND ALFRED SOMMER ${ }^{2}$ \\ From the 'Eye Department, Mvumi Hospital, Dodoma, Tanzania, and the 2 ICEPO, Dana Centre for \\ Preventive Ophthalmology, Johns Hopkins Medical Institution, Baltimore, USA
}

SUMMARY One hundred and thirty Tanzanian children with corneal ulceration were clinically examined to determine the cause of the ulceration. $37 \%$ of the ulcers were associated with recent measles infection and $38 \%$ of the children had bilateral ulceration. Herpes simplex virus infection was the commonest cause of ulceration in the series, but vitamin A deficiency was the major cause of bilateral ulceration, subsequent blindness, and mortality in this series. Other significant causes of childhood corneal ulceration were the use of traditional eye medicines, confluent measles keratitis, and ophthalmia neonatorum. We discuss the various mechanisms by which measles causes corneal ulceration, and the priorities in prevention and management of corneal ulceration in African children.

Xerophthalmia, a term used to describe the ocular findings caused by vitamin A deficiency, remains one of the six commonest blinding diseases in the world today and the commonest cause of blindness in children. ${ }^{12}$

The problem of childhood blindness due to xerophthalmia has been well established in Indonesia ${ }^{3}$ and other parts of Asia. ${ }^{+7}$ In Africa, however, although $70 \%$ of blind school children are blind from corneal scarring, ${ }^{,-11}$ there is still uncertainty over the relative importance and interaction of factors such as measles infection, " vitamin A deficiency, ${ }^{12-18}$ herpes simplex keratitis, ${ }^{1019}$ and the use of traditional eye medicines $^{821222}$ in causing childhood ulceration and corneal blindness.

To investigate this problem we carried out a hospital based study with the aim of identifying by clinical means: (1) the major causes of corneal ulceration in Tanzanian children, (2) the mechanisms by which measles may lead to corneal ulceration, and (3) the major pathways leading to blindness from corneal scarring in children.

\section{Patients and methods}

One of us (AF) examined 130 children aged 4 days to 10 years presenting with corneal ulceration to the eye

Correspondence to Allen Foster, International Centre for Eye Health, 27-29 Cayton Strect, London EC1V 9EJ. department of Mvumi Hospital in Central Tanzania between October 1981 and June 1985.

All the children were admitted to hospital and basic demographic and historical information documented on a standard form. This included name, age, sex, village of residence, date ulcer first noted, history of measles, use of traditional eye medicines, recent diet, and history of night blindness. Ocular examination with a handlight, lid speculum, fluorescein, and, in co-operative children, slit-lamp microscopy was performed, and photographs were taken of the corneal ulcers. Nutritional status was determined by comparing their weight for age against the Harvard standards. The child was considered normal (well nourished) if his weight for age was greater than $80 \%$ of standard, underweight if $60-80 \%$ of standard, and marasmic if less than $60 \%$ weight for age.

For this special investigation serum samples were drawn for chemical analysis on 41 consecutive cases of the 130 cases in this report. They were also obtained from three controls for each of the children with a diagnosis of measles-associated xerophthalmic corneal ulceration, matched on age, sex, and the presence of measles. The serum was kept frozen until shipment to Baltimore, where it was analysed by high-performance liquid chromatography (HPLC). These values were not used in arriving at the clinical diagnosis. 


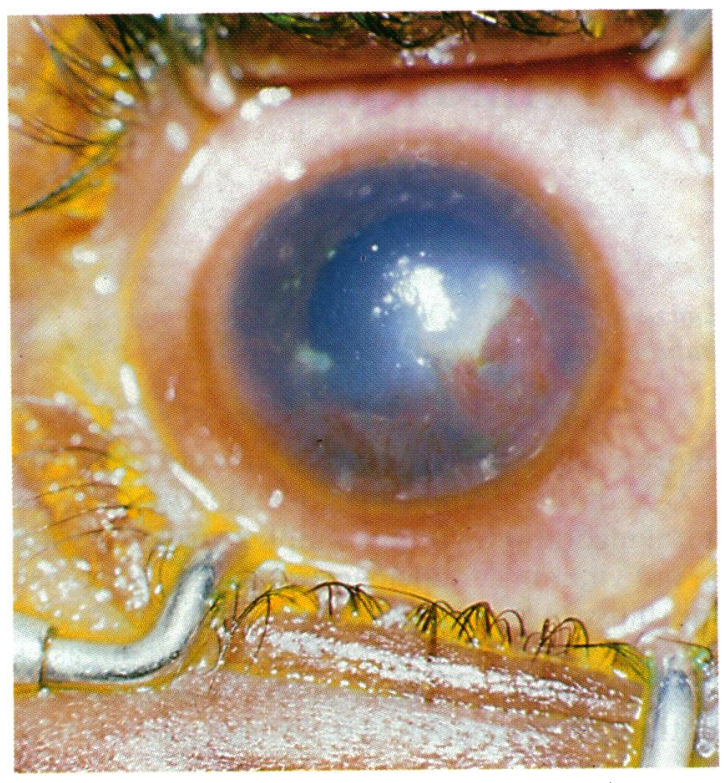

Fig. 1 Case 1. Right eye of a 2-year-old-girl, showing an irregular corneal ulcer with severe corneal vascularisation.

From the history and morphological appearance of the ulcer $^{2324}$ a provisional diagnosis was made. Specific treatment was then initiated according to the following protocol:

\begin{tabular}{|c|c|}
\hline $\begin{array}{l}\text { Diagnosis } \\
\text { Herpes simplex }\end{array}$ & $\begin{array}{l}\text { Treatment } \\
\text { Idoxuridine } 0 \cdot 1 \% \text { drops hourly or } 0.5 \% \\
\text { ointment, } 5 \text { times daily. }\end{array}$ \\
\hline Xerophthalmia & $\begin{array}{l}\text { Vitamin A } 200000 \text { IU oral stat, repeat } \\
\text { after } 1 \text { day and } 1 \text { week. }\end{array}$ \\
\hline Bacterial ulcer & $\begin{array}{l}\text { Chloramphenicol } 1 \% \text { drops hourly, } \\
\text { with or without } 20 \mathrm{mg} \text { subconjunctival } \\
\text { gentamicin. }\end{array}$ \\
\hline $\begin{array}{l}\text { Trachoma } \\
\text { Ophthalmia neonatorum }\end{array}$ & $\begin{array}{l}\text { Tetracycline } 1 \% \text { ointment } 3 \text { times a day. } \\
\text { Chloramphenicol } 1 \% \text { drops hourly, } \\
\text { with tetracycline } 1 \% \text { ointment } 3 \text { times a } \\
\text { day. }\end{array}$ \\
\hline Exposure keratopathy & $\begin{array}{l}\text { Tetracycline } 1 \% \text { ointment stat with eye } \\
\text { pad for } 1 \text { day. }\end{array}$ \\
\hline Traditional eye medicines & $\begin{array}{l}\text { Chloramphenicol } 1 \% \text { drops hourly, } \\
\text { with hydrocortisone } 1 \% \text { drops } 3 \text { times a } \\
\text { day after } 48 \text { hours. }\end{array}$ \\
\hline
\end{tabular}

The child continued to receive a normal diet from the mother unless there was evidence of severe undernutrition, in which case additional food was given in the form of dried skimmed milk, eggs, and oil. Children with diarrhoea received oral rehydration therapy and children with respiratory infections received systemic antibiotics, usually procaine penicillin. Preparations containing multivitamins were not given.

After 24, 48, and 72 hours the child was reexamined, and, depending on response to therapy and clinical appearance of the ulcer, the management

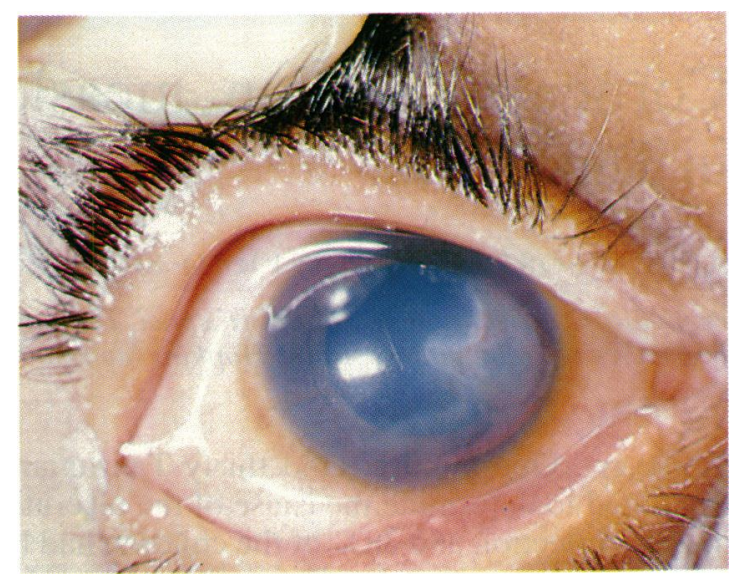

Fig. 2 Case 1. Right eye of a 2-year-old girl following nine days' treatment with IDU. The ulcer has healed, leaving a superficial corneal scar.

was continued or modified according to the protocol. At discharge a final diagnosis of the aetiology of the corneal ulcer was made based on the history, the clinical appearance of the ulcer, and the response to specific therapy under supervision, as shown in the following case presentations.

\section{Case reports}

\section{CASE 1}

A 2-year-old girl was admitted with a painful red right eye of at least two weeks' duration. There was no history of measles infection, but she had received chloramphenicol drops for one week to her right eye. On examination she was well nourished, with a normal left eye. The right eye showed an irregularly shaped linear ulcer in the inferonasal quadrant with surrounding stromal oedema and marked vascularisation. There were also several small areas of superficial staining temporally. There was no perforation (Fig. 1). She was treated with $0.5 \%$ idoxuridine (IDU) ointment five times a day and gradually improved. Treatment was stopped after nine days, leaving a residual partial-thickness, nasally situated corneal scar (Fig. 2). Three days later a small area of staining recurred which was successfully treated with a further five days' course of IDU.

Diagnosis. Herpes simplex ulceration of the right cornea.

\section{CASE 2}

A 20-month-old boy was admitted on 14 April 1984 with a three-week history of measles. There was no history of night blindness, and the mother denied using traditional eye medicines. On examination he was marasmic. The right eye showed limbus-to- 


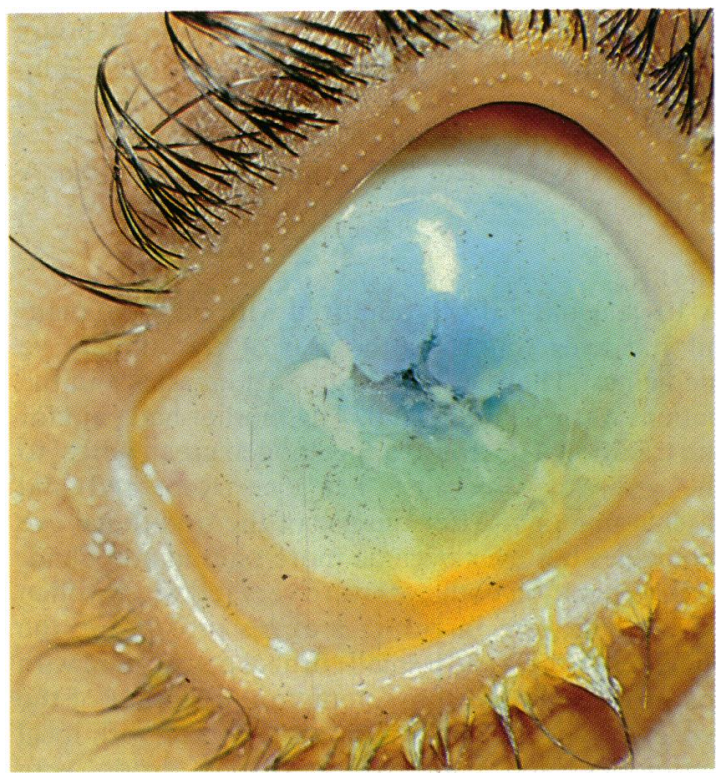

Fig. 3 Case 2. Right eye of a 20-month-old boy with measles and marasmus. There is limbus to limbus corneal necrosis with a central corneal perforation.

limbus corneal necrosis with perforation of the central cornea (Fig. 3). The left eye showed sloughing of the cornea with prolapse of iris and vitreous (Fig. 4). The child was treated with oral vitamin A, frequent calorie-protein rich meals, and systemic antibiotics. He died 10 days after admission of

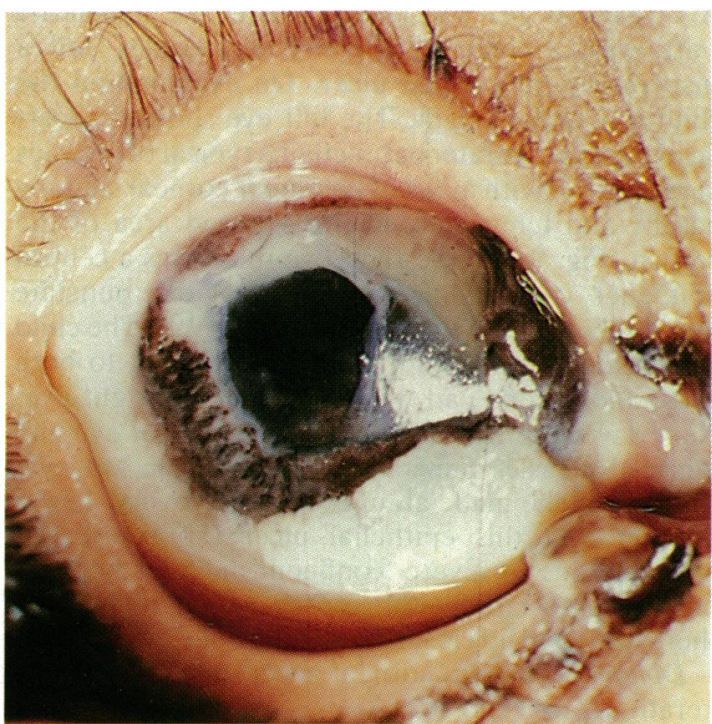

Fig. 4 Case 2. Left eye of a 20-month-old boy with measles and marasmus. There is complete sloughing of the cornea with prolapse of iris and vitreous.

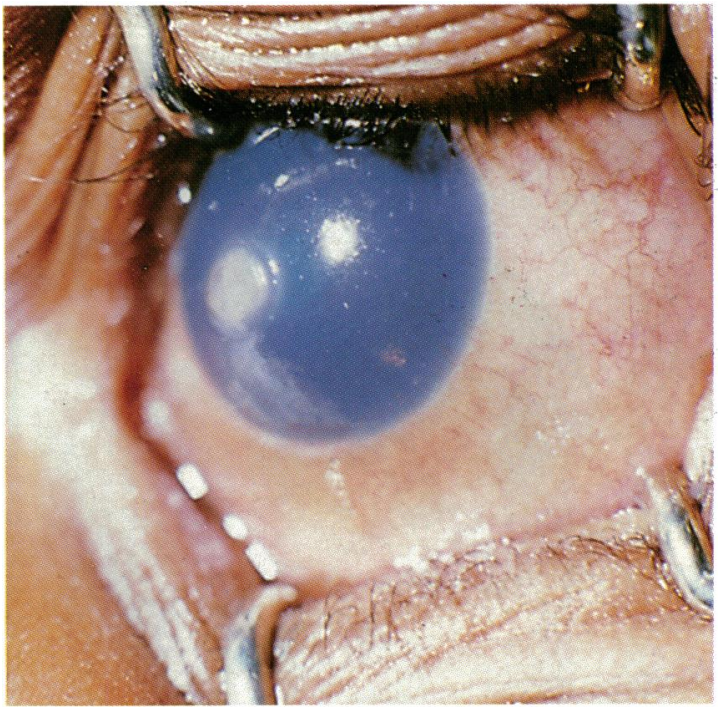

Fig. 5 Case 3. Left eye of an 18-month-old boy showing corneal xerosis and localised areas of stromal necrosis.

pneumonia, at which time the right eye was developing a staphyloma and the left eye was phthsical. Serum vitamin was $40 \mu \mathrm{g} / \mathrm{l}$ (normal $200 \mu \mathrm{g} / \mathrm{l}$ or above), and serum albumin $29 \mathrm{~g} / \mathrm{l}$ (normal $40 \mathrm{~g} / \mathrm{l}$ ).

Diagnosis. Postmeasles marasmus, with bilateral corneal ulceration due to vitamin A deficiency.

CASE 3

An 18-month-old boy was admitted on 24 October

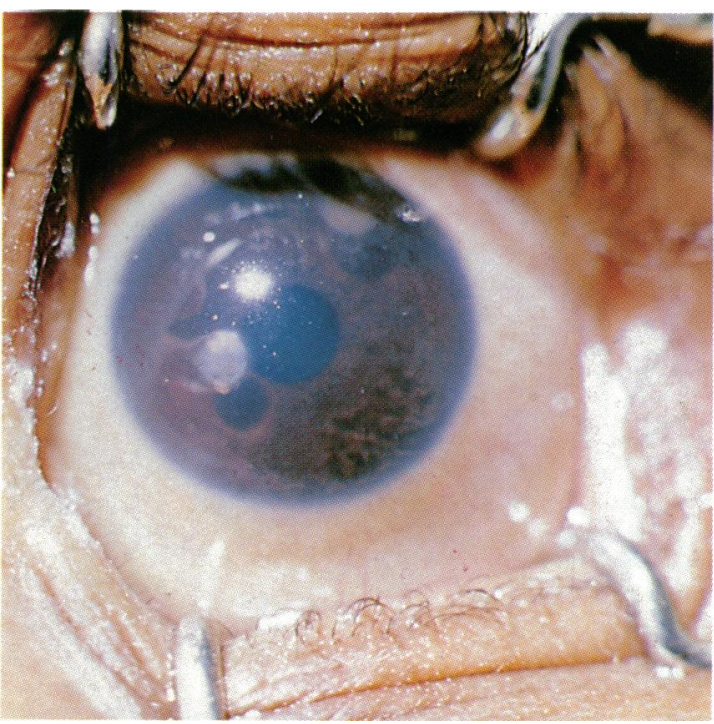

Fig. 6 Case 3. Same as Fig. 5, five days after treatment with vitamin A. The cornea is now clear, and the areas of stomal necrosis have healed with scar formation. 


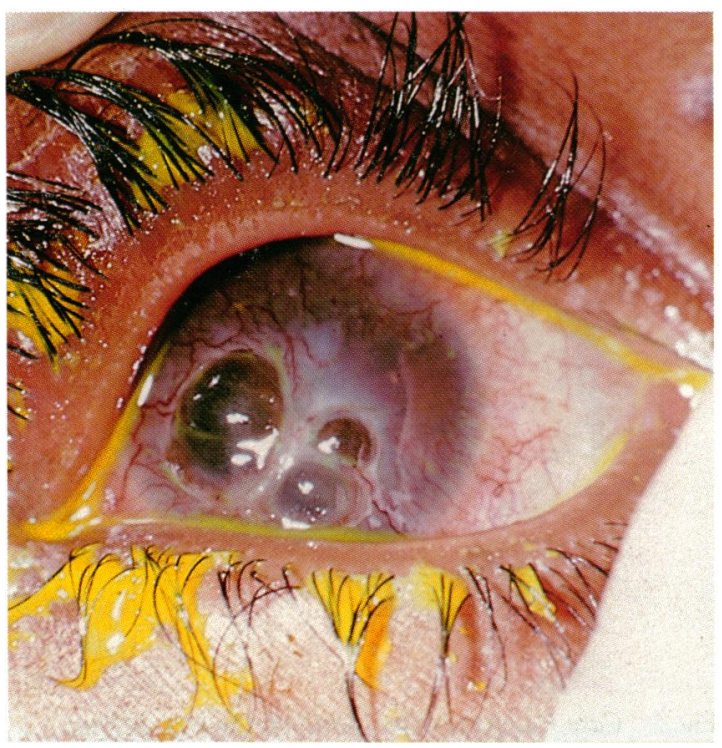

Fig. 7 Case 4. Right eye of a 10-year-old girl afier application of traditional eye medicines. There are three areas of descematocoele formation with marked corneal vascularisation.

1984. He had suffered from measles six months previously and was underweight. On examination there was bilateral xerosis of the conjunctiva and cornea. In the left eye there were small circular areas of stromal necrosis in the nasal and upper temporal areas of the cornea (Fig. 5). He was given standard

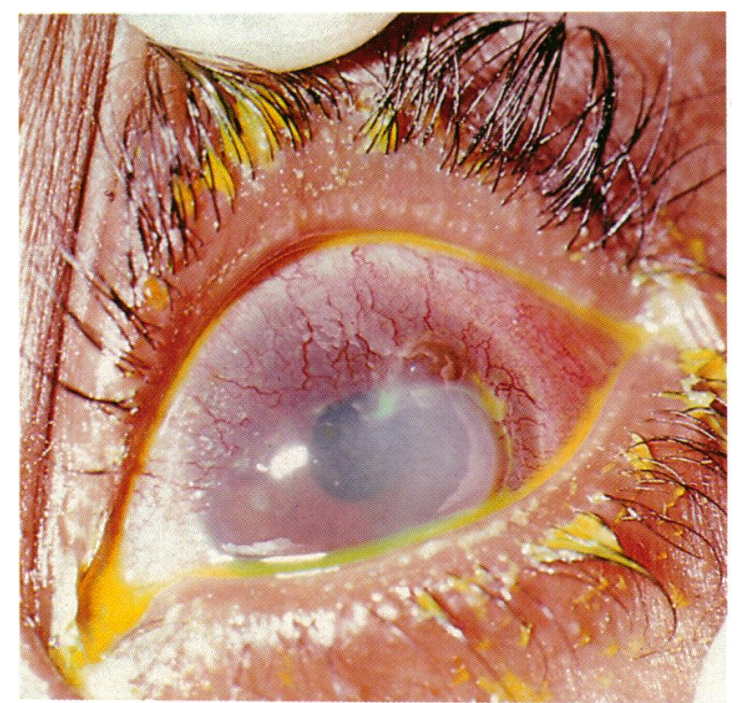

Fig. 8 Case 4. Left eye of a 10-year-old girl after application of traditional eye medicines. There is one area of descematocoele formation with corneal vascularisation. vitamin A therapy, with improvement after 48 hours and healing with scar formation after five days (Fig. 6). Serum vitamin A was $20 \mu \mathrm{g} / \mathrm{l}$ (normal above 200 $\mu \mathrm{g} / \mathrm{l}$ ), and serum albumin $28 \mathrm{~g} / \mathrm{l}$ (normal $40 \mathrm{~g} / \mathrm{l}$ ).

Diagnosis. Corneal ulceration due to vitamin A deficiency.

\section{CASE 4}

A 10-year-old girl was admitted with bilateral painful red eyes following the use of traditional eye medicines. There was no history of measles and the patient was well nourished. The mother had paid for the traditional doctor to apply 'boiled green herbs' to the girl's eyes because her eyes were red and discharging pus. After the use of the traditional eye medicines her eyes became more painful and blind. On examination both eyes were very red with swollen lids. There were three areas of iris prolapse in the right eye (Fig. 7) and a small corneal perforation with iris prolapse in the superotemporal quadrant of the left eye (Fig. 8). The patient was treated with local antibiotics, and later hydrocortisone drops were added. At discharge, 15 days later, the right eye had an adherent central leucoma with projection of light vision only, and the left eye 6/18 vision with a vascularised peripheral adherent leucoma. Serum vitamin A was $300 \mu \mathrm{g} / \mathrm{l}$ (normal above $200 \mu \mathrm{g} / \mathrm{l}$ ), and serum albumin $54 \mathrm{~g} / \mathrm{l}$ (normal $40 \mathrm{~g} / \mathrm{l}$ ).

Diagnosis. Bilateral corneal ulceration due to traditional eye medicines.

\section{CASE 5}

A 2-year-old girl was referred from the paediatric ward with a three-day history of measles and a suspected right corneal ulcer. On examination the child was underweight. The left eye showed superficial punctate keratoconjunctivitis typical of measles keratitis, but with areas of confluent corneal staining nasally and temporally in the exposed area of the cornea (Fig. 9). In the right eye there was a central epithelial corneal ulcer with areas of punctate measles keratitis in the periphery (Fig. 10). The child was treated with tetracycline eye ointment to both eyes, and an eye pad was applied to the right eye. Next day there was no staining in the right eye and minimal measles punctate keratitis in the left eye. Thereafter she made an uneventful recovery. It was thought that this epithelial ulcer (abrasion) was probably due to severe 'confluent' measles keratitis possibly associated with exposure, though clinically there was good lid closure at the time of examination.

Diagnosis. Right corneal ulcer due to measles keratitis (plus exposure).

CASES 6 AND 7

Female twins, $A$ and $B$, aged 11 months were 


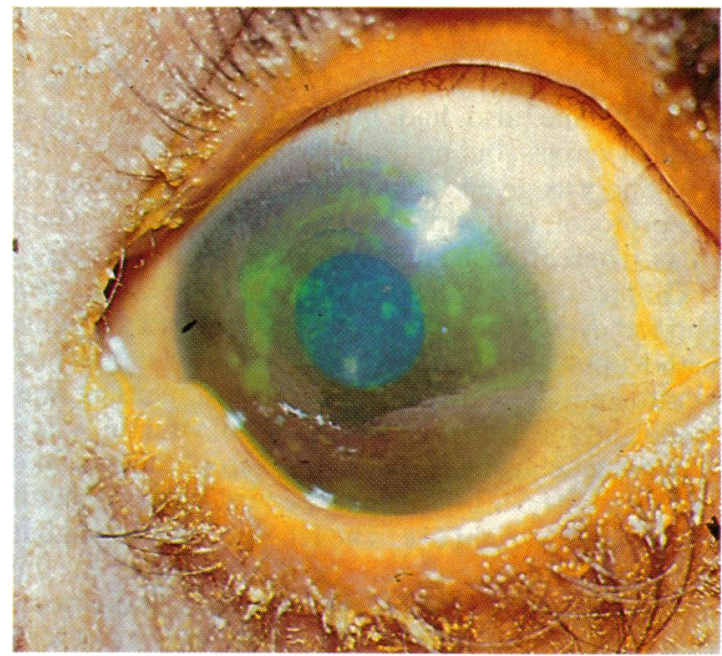

Fig. 9 Case 5. Left eye of a 2-year-old girl with measles. There are areas of epithelial staining in the mid-nasal and temporal areas, with peripheral punctate keratitis.

admitted on 9 April 1984. There was no history of measles, but both twins were marasmic. On examination there was a dendritic ulcer in the right eye (Fig. 11 ), and a geographic ulcer in the left eye of twin A (case 6). Twin B (case 7) had an extensive central geographic ulcer in the right eye and a peripheral geographic ulcer in the left eye (Fig. 12). Both twins were treated with IDU ointment; they were also given oral rehydration solution and systemic antibiotics for gastroenteritis and pneumonia. Twin A's

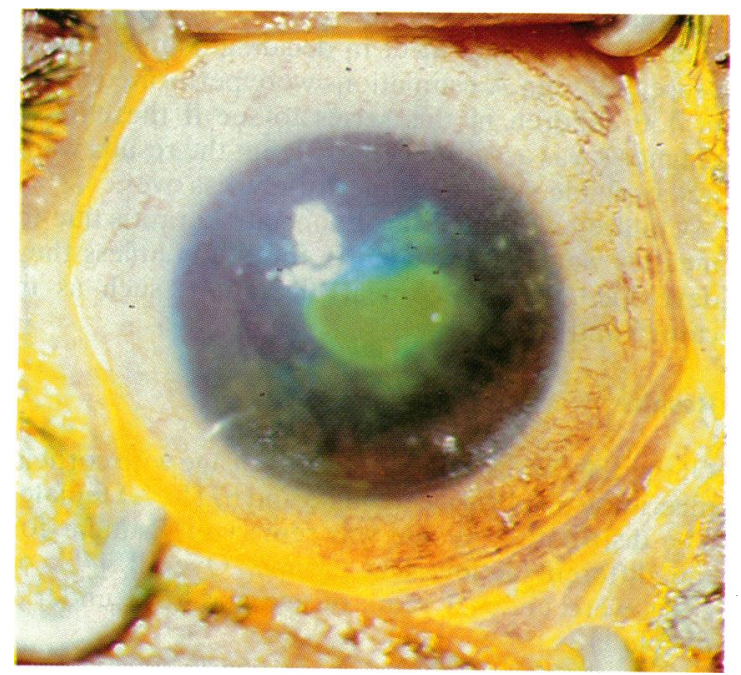

Fig. 10 Case 5. Right eye of a 2-year-old girl with measles. There is a central epithelial ulcer, with a few areas of punctate keratitis in the periphery.

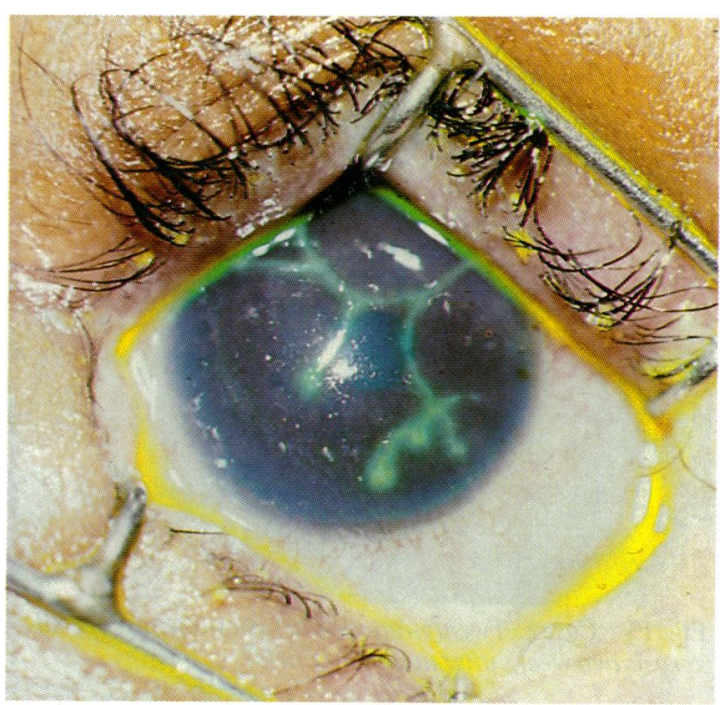

Fig. 11 Case 6. A dendritic ulcer of the right eye in an 11month-old marasmic girl (twin A).

eyes slowly improved over 14 days, so that on 23 April 1984 there was minimal scarring in the right eye and a small area of residual staining with superficial scarring in the left eye. Twin B improved rapidly initially, and within four days of starting IDU there was minimal staining in both eyes. However, despite continued treatment with IDU the herpetic ulcers recurred, especially in her right eye. Twin B died of pneumonia on 23 April 1984, and twin A died 24 hours later of pneumonia and gastroenteritis.

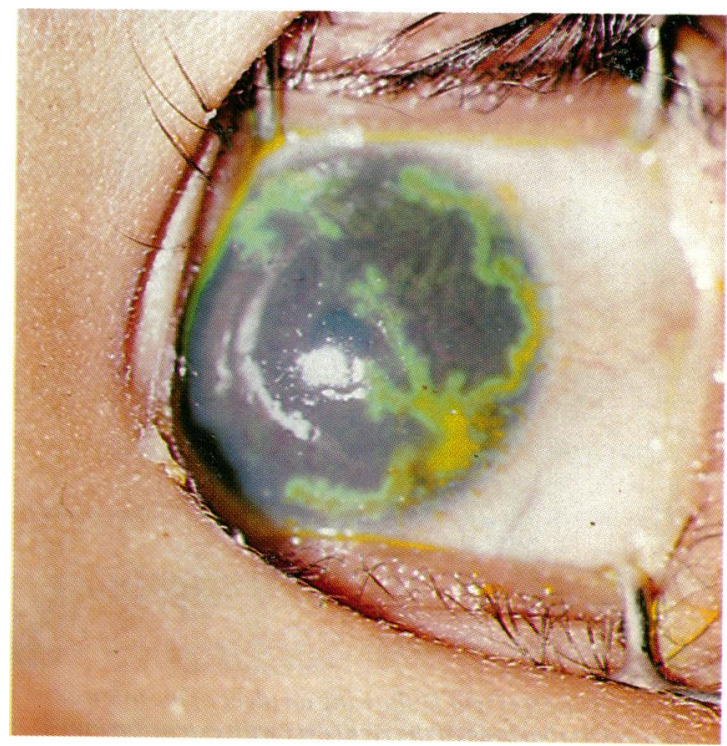

Fig. 12 Case 7. A peripheral geographic ulcer (twin B). 


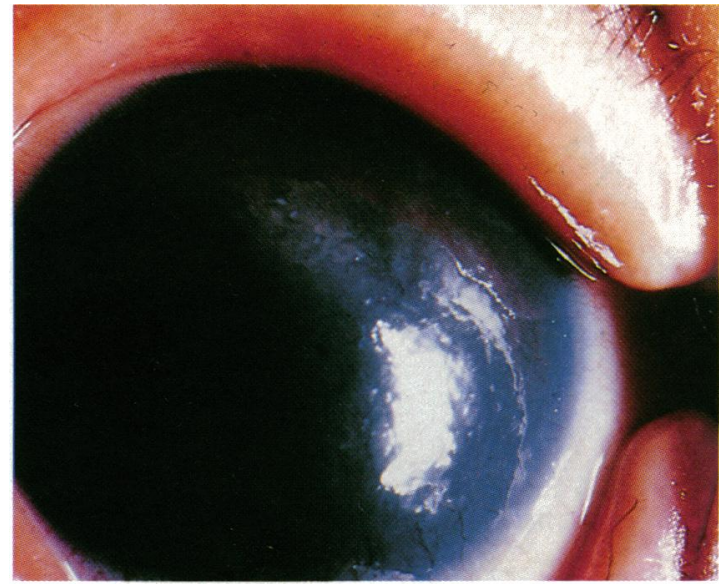

Fig. 13 Case 8. Twenty-month-old twin showing corneal xerosis two weeks after measles (twin C).

Diagnosis. Bilateral corneal ulceration in twins due to herpes simplex virus. The cause of death was pneumonia and gastroenteritis (? due to herpes simplex) with marasmus.

CASES 8 AND 9

Female twins aged 20 months were first seen on 22 February 1984. Twin C (case 8) was admitted on the paediatric ward, recovering from measles infection

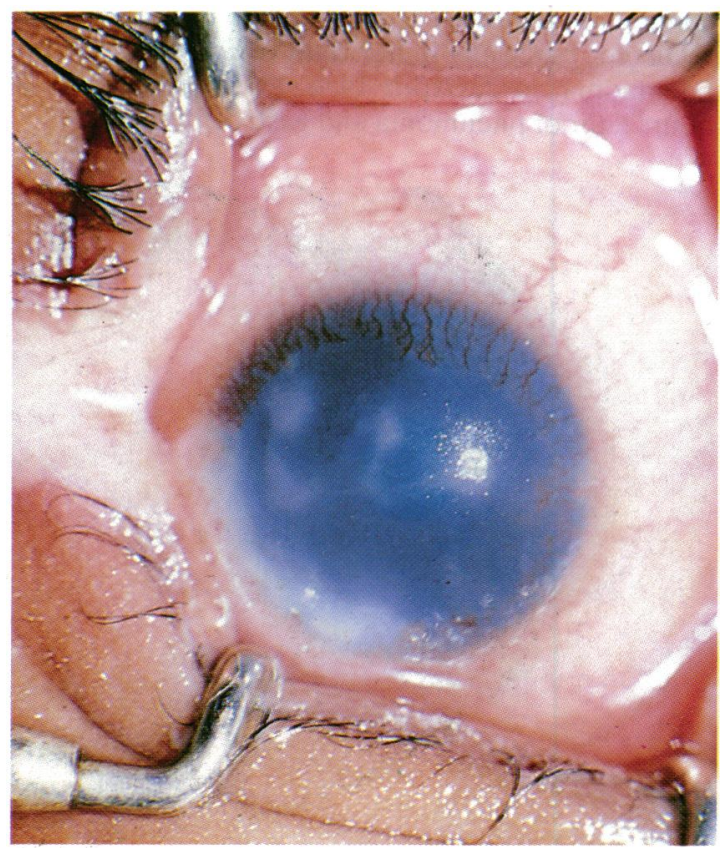

Fig. 14 Case 9. Twin D showing an ulcer of the inferior temporal limbal area of the right eye, with extension into a central dendritic ulcer. which had started two weeks previously. On examination she was underweight with small ulcers on her lips, face, ear, and scalp typical of herpes simplex. She also had bilateral conjunctival and corneal xerosis, but no frank corneal ulceration (Fig. 13). She was given vitamin A therapy according to the protocol, and within 48 hours both corneas were clear. Thereafter she made an uneventful recovery.

On the same day twin D (case 9) developed fever and red eyes. On examination she was underweight, with Koplik's spots and bilateral superficial punctate keratoconjunctivitis. A diagnosis of measles was made and she was given 200000 IU of vitamin A as a prophylactic against developing xerophthalmia like her twin sister. Six days later she was seen again with a watering red right eye. The left eye was normal but the right eye showed a branching ulcer in the inferotemporal quadrant of the cornea and ulceration of the lateral canthus (Fig. 14). She was treated with IDU drops and gradually improved over six days (Fig. 15). Treatment was stopped on 6 March 1984 and both twins discharged home. It seems likely that twin D was infected with measles and possibly also herpes simplex virus by twin C.

Diagnosis. Twin $\mathrm{C}$ had measles associated xerophthalmia (corneal xerosis), with cutaneous herpes simplex. Twin D had measles associated with herpes simplex ulceration of the right cornea.

In many rural areas of the developing world, such as Mvumi Hospital, rapid and accurate microbiological and biochemical investigations are not available and cannot be relied upon in the diagnosis and management of corneal ulceration. It is therefore necessary to place great emphasis on the history and a careful examination of the morphological appearance of the corneal ulcer in deciding its most likely cause. Vitamin A estimations were performed on 41 of 130 children in this series to see if the clinical diagnosis was accurate (Fig. 16), but the results were not available until the clinical study was over.

Children with superficial punctate keratitis due to measles were not included in this study unless they developed definite corneal ulceration, such as in cases 5 and 9.

\section{Results}

Of the 130 children under 11 years of age with corneal ulceration $63(48 \%)$ were male and $67(52 \%)$ female. The distribution by age was remarkably similar for the different aetiological groups. Overall $47 \%$ of cases were under 2 years of age and $76 \%$ under 5 (Table 1).

Our clinical diagnoses were nearly always supported by serum vitamin A levels obtained prior to treatment (Fig. 16). The occasional discrepancy 


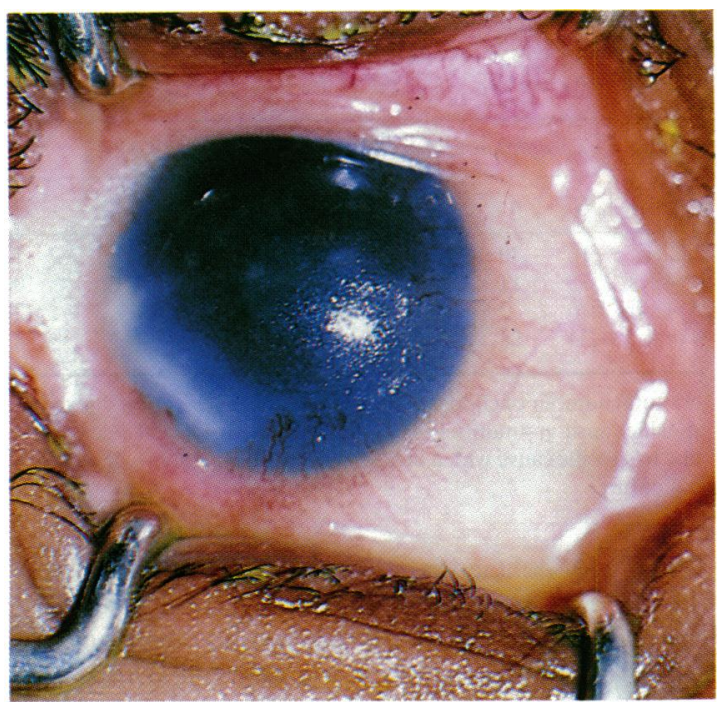

Fig. 15 Case 9. Same as Fig. 14, six days after starting IDU treatment.

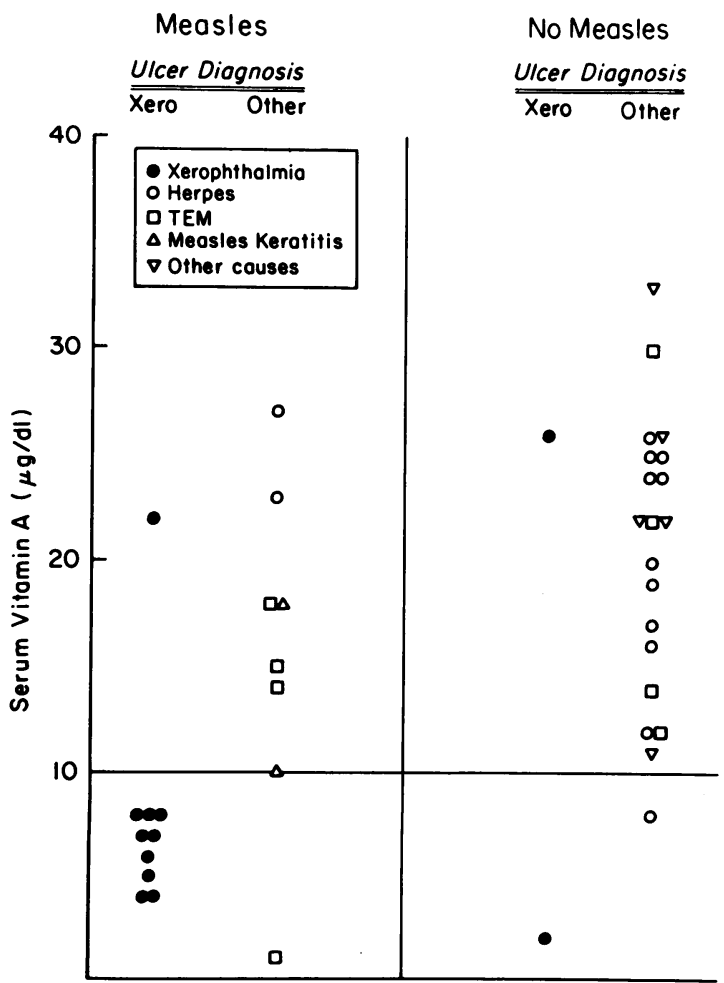

Fig. 16 Serum vitamin A levels on 40 consecutive children with corneal ulcers. One additional child, with clinical diagnosis of xerophthalmia, received vitamin A before serum was obtained. Diagnosis established on clinical grounds as described in 'Methods', before serum vitamin A levels were available. (SI conversion: $\mu \mathrm{g} / \mathrm{dl} \times 10=\mu \mathrm{g} / \mathrm{l})$.

Table 1 Aetiology of corneal ulceration by age in 130 Tanzanian children

\begin{tabular}{lrrll}
\hline Cause & No. & $\begin{array}{l}<2 \text { years } \\
\%\end{array}$ & $\begin{array}{l}2-4 \text { years } \\
\%\end{array}$ & $\begin{array}{l}5-10 \text { years } \\
\%\end{array}$ \\
\hline Vitamin A deficiency & 34 & 47 & 35 & 18 \\
Herpes Simplex & 47 & 51 & 21 & 28 \\
Traditional Eye Med & 18 & 44 & 28 & 28 \\
Other known causes & 21 & 57 & 19 & 24 \\
Measles confluent keratitis & 5 & 20 & 60 & 20 \\
Unknown & 5 & 0 & 80 & 20 \\
Total & 130 & 47 & 29 & 24 \\
\hline
\end{tabular}

illustrates the potential complexity and multifactorial nature of corneal ulceration in this group of children. Of the two children with a clinical diagnosis of xerophthalmia, but normal vitamin $\mathrm{A}$, the one with measles had bilateral perforating ulcers and the one without measles a unilateral ulcer that seemed to respond to vitamin A. In retrospect both cases may have been caused by the use of traditional eye medicines. One case of measles associated with corneal ulceration not diagnosed as xerophthalmia had extremely low serum levels of vitamin A and retinal binding protein. The patient had initially been diagnosed as vitamin A deficiency with evidence or traditional medicine in the lower fornix. As he did not respond to vitamin A the final clinical diagnosis was changed to traditional eye medicine. Obviously there is no reason why the child could not have had both. Mean serum vitamin A on the eight xerophthalmic children with measles was $68 \mu \mathrm{g} / \mathrm{l}$ and for their 24 matched controls $102 \mu \mathrm{g} / \mathrm{l}(\mathrm{p}<0.01)$.

The single commonest cause of corneal ulceration was infection with herpes simplex virus (HSV) accounting for over one-third of all cases. Vitamin A deficiency (xerophthalmia) was responsible for a quarter of the ulcers, and the use of traditional eye medicines (TEM) for nearly $14 \%$. Other causes included bacterial ulceration (10 cases), trauma (three), ophthalmia neonatorum (three), trachoma (three), and exposure ulceration of the cornea (two) due to proptosis from orbital swellings. In 10 children

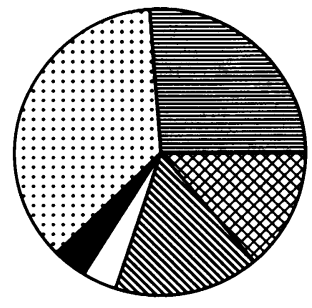

All Ulcers $\mathbf{n}=\mathbf{1 3 0}$

Fig. 17 Aetiology of corneal ulceration in 130 Tanzanian children with corneal ulcers. 


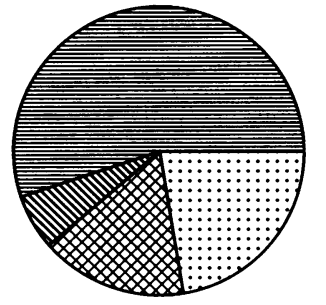

Vitamin A Deficiency $(55.1 \%)$

$\mathbb{N}$ Other $(6.2 \%)$

Traditional Medicines $(16.3 \%)$

Herpes Simplex $(22.4 \%)$

\section{Bilateral Ulcers $\mathbf{n}=\mathbf{4 9}$}

Fig. 18 Aetiology of corneal ulceration in 49 Tanzanian children with bilateral corneal ulcers.

no definite cause could be given. Two of these 10 children absconded before response to therapy could be assessed, a further three had nondescript superficial erosions unrelated to measles, and the remaining five had areas of epithelial ulceration within 10 days of measles infection, as demonstrated by case 5 , which were attributed to measles 'confluent' keratitis (Fig. 17).

In $38 \%$ of children the corneal ulceration was bilateral. Vitamin A deficiency was responsible for over a half of the bilateral cases, and herpes simplex for nearly a quarter. The remaining 11 cases were due to the use of TEM (eight cases) and ophthalmia neonatorum (three cases) (Fig. 18).

There was a history of measles infection within one month before developing corneal ulceration in $37 \%$ of the 130 children and in $57 \%$ ( 28 of 49 ) of those with bilateral ulceration. Vitamin A deficiency was responsible for half of the measles-associated corneal ulcers, herpes simplex for one-fifth, and TEM for nearly $17 \%$. Five of the 48 children with measlesrelated ulceration showed superficial central corneal staining, which was thought to be caused by either a severe 'confluent form' of measles keratitis or exposure keratopathy (Fig. 19). One child with a perforated corneal ulcer one month after measles and a history of using TEM absconded before the effects of therapy could be seen.

Recent measles infection was associated with nearly three-quarters of corneal ulcers caused by

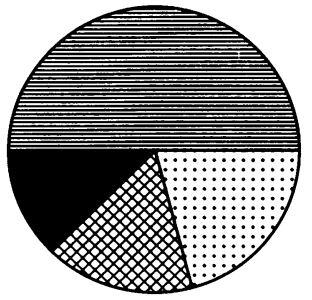

Vitamin A Deficiency $(50 \%)$

Measles $(12.5 \%)$

$\otimes$ Traditional Medicines $(16.7 \%)$

: Herpes Simplex $(20.8 \%)$

Post-Measles Ulcers $\mathbf{n}=48$

Fig. 19 Aetiology of corneal ulceration in 48 Tanzanian children with measles-associated corneal ulceration.
Table 2 Corneal ulceration within one month of measles infection, by cause and age as a percentage of all ulcers, in Tanzanian children

\begin{tabular}{|c|c|c|c|c|c|c|c|c|c|}
\hline \multirow[t]{2}{*}{ Age } & \multicolumn{3}{|c|}{ Xerophthalmia } & \multicolumn{3}{|c|}{ Herpes simplex } & \multicolumn{3}{|c|}{$T E M$} \\
\hline & $N$ & $n$ & $\%$ & $N$ & $n$ & $\%$ & $N$ & $n$ & $\%$ \\
\hline$<2$ yrs & 16 & 10 & 62 & 24 & 3 & 12 & 8 & 1 & 12 \\
\hline $2-4$ yrs & 12 & 11 & 92 & 10 & 3 & 30 & 5 & 5 & 100 \\
\hline $5-10 \mathrm{yrs}$ & 6 & 3 & 50 & 13 & 4 & 31 & 5 & 2 & 20 \\
\hline Total & 34 & 24 & 71 & 47 & 10 & 21 & 18 & 8 & 44 \\
\hline
\end{tabular}

$\mathrm{N}=$ total number of children seen with corneal ulceration due to specific cause. $n=$ number of children seen with corneal ulceration due to specific cause which developed within one month of measles infection.

vitamin A deficiency, almost a half of those due to TEM, and one-fifth of ulcers caused by herpes simplex (Table 2). Measles infection was associated with $29 \%$ of corneal ulcers in under 2 -year-olds, $70 \%$ in 2-4-year-olds, and 37\% in 5-10-year-old children. $92 \%$ of xerophthalmic ulcers and all TEM ulcers in children 2 to 4 years old were associated with measles.

The longer the duration between onset of measles and presentation, the more likely the ulceration was due to vitamin A deficiency. $63 \%$ of ulcers occurring within seven days of measles onset were due to causes other than vitamin A deficiency, while $56 \%$ of cases occurring two weeks or later after measles were due to vitamin A deficiency. $70 \%$ of measles-associated herpes simplex ulcers occurred within 14 days of the onset of measles rash.

Over half (11 of 20$)$ of the unilateral cases of postmeasles corneal ulcers involved the corneal stroma, while $82 \%$ ( 23 of 28 ) of the bilateral cases showed involvement of the stroma in at least one eye, and seven children showed total bilateral corneal necrosis (Table 3 ).

Table 3 Clinical appearance of active corneal ulceration occurring within one month of measles infection in 48 Tanzanian children

\begin{tabular}{|c|c|c|c|c|}
\hline \multirow[t]{2}{*}{ Type of ulcer } & \multicolumn{2}{|c|}{ Unilateral } & \multicolumn{2}{|c|}{ Bilateral } \\
\hline & $n$ & $\%$ & $n$ & $\%$ \\
\hline \multicolumn{5}{|l|}{ Epithelial: } \\
\hline dendritic ulcer & 1 & 2 & 0 & 0 \\
\hline geographic ulcer & 3 & 6 & 3 & 6 \\
\hline central abrasion & 5 & 10 & 0 & 0 \\
\hline xerosis with stain & 0 & 0 & $2(1)$ & 4 \\
\hline \multicolumn{5}{|l|}{ Stromal: } \\
\hline non-perforated ulcer & 8 & 17 & $6(1)$ & 13 \\
\hline perforated ulcer & 3 & 6 & 10 & 21 \\
\hline total corneal necrosis & 0 & 0 & $7(4)$ & 15 \\
\hline Total & 20 & 41 & $28(6)$ & 59 \\
\hline
\end{tabular}

( ) =Number of children who died. 
Table 4 Clinical appearance of active corneal ulceration due to vitamin A deficiency in 34 Tanzanian children

\begin{tabular}{|c|c|c|c|c|c|c|}
\hline \multirow[t]{2}{*}{ Type of ulcer } & \multicolumn{2}{|c|}{ Non-measles } & \multicolumn{2}{|c|}{ Measles } & \multicolumn{2}{|c|}{ Total } \\
\hline & Uni. & $B i$. & Uni. & $B i$ & $N$ & $\%$ \\
\hline Corneal xerosis & 0 & 0 & 0 & $2(1)$ & 2 & $6 \cdot 0$ \\
\hline $\begin{array}{l}\text { Non-perforated } \\
\text { round, oval ulcers }\end{array}$ & 3 & 1 & 3 & $6(1)$ & 13 & $38 \cdot 2$ \\
\hline $\begin{array}{l}\text { Perforated round, } \\
\text { oval ulcers }\end{array}$ & 0 & $3(2)$ & 1 & 5 & 9 & $26 \cdot 4$ \\
\hline $\begin{array}{l}\text { Total corneal } \\
\text { necrosis }\end{array}$ & 0 & $3(2)$ & 0 & $7(4)$ & 10 & $29 \cdot 4$ \\
\hline Totals & $\begin{array}{l}3 \\
8 \cdot 8 \%\end{array}$ & $\begin{array}{c}7(4) \\
20 \cdot 6 \%\end{array}$ & $\begin{array}{c}4 \\
11 \cdot 8 \%\end{array}$ & $\begin{array}{l}20(6) \\
58 \cdot 8 \%\end{array}$ & 34 & $100 \cdot 0$ \\
\hline
\end{tabular}

( ) =Number of children who died. Uni. = unilateral. $\mathrm{Bi} .=$ bilateral.

Six children with corneal ulceration following measles died $(12.5 \%)$, of which all had bilateral ulceration and four had total bilateral corneal necrosis.

The clinical appearance of the ulcers caused by vitamin A deficiency and herpes simplex is given in Tables 4 and 5. Bilateral involvement of measlesassociated ulcers was seen in $83 \%$ ( 20 of 24$)$ of cases due to vitamin A deficiency, but only $30 \%$ (three of 10 ) of the ulcers due to herpes simplex infection. A geographic type of corneal ulcer was the commonest pattern of herpetic ulceration, occurring in $51 \%$ (24 of 47) of cases, with a dendritic pattern being seen in only $25 \%$ ( 12 of 47 ) (Table 5).

The overall mortality in hospital was $10 \cdot 8 \%$, but nearly one in three of the children with corneal ulcers due to vitamin A deficiency died despite hospital admission and management (Table 6). Sixteen children (six of whom died) were judged to have bilateral corneal lesions which would result in blindness (binocular vision of less than 3/60), of which 11 $(69 \%)$ were due to vitamin A deficiency and three $(19 \%)$ to the use of TEM.

Corneal ulceration induced by vitamin A deficiency usually occurred after measles (76\% of cases), was bilateral in $79 \%$, and was associated with high mortality (29\%) and blindness (32\%). In

Table 5 Clinical appearance of active corneal ulceration due to herpes simplex virus in 47 Tanzanian children

\begin{tabular}{|c|c|c|c|c|c|c|}
\hline \multirow[t]{2}{*}{ Type of ulcer } & \multicolumn{2}{|c|}{ Non-measles } & \multicolumn{2}{|c|}{ Measles } & \multicolumn{2}{|c|}{ Total } \\
\hline & Uni. & $B i$ & Uni. & $B i$ & $N$ & $\%$ \\
\hline Dendritic & 8 & 3 & $1(1)$ & 0 & 12 & $25 \cdot 5$ \\
\hline Gcographic & 14 & $4(2)$ & 3 & 2 & 24 & $51 \cdot 1$ \\
\hline Atypical limbal & 5 & 0 & 3 & 0 & 8 & $17 \cdot 0$ \\
\hline Decp stromal & 2 & 1 & 0 & 0 & 3 & 6.4 \\
\hline \multirow[t]{2}{*}{ Totals } & 29 & $8(2)$ & $7(1)$ & 3 & 47 & $100 \cdot 0$ \\
\hline & $61 \cdot 7 \%$ & $17 \cdot 0 \%$ & $14 \cdot 9 \%$ & $6.4 \%$ & & \\
\hline
\end{tabular}

( ) = Number of children who died. Uni. = unilateral. Bi. =bilateral.
Table 6 Characteristics of the different causes of corneal ulceration in Tanzanian children

\begin{tabular}{|c|c|c|c|c|c|c|c|c|c|}
\hline \multirow[t]{2}{*}{ Cause } & \multirow[t]{2}{*}{ No. } & \multicolumn{2}{|c|}{ Bilateral } & \multicolumn{2}{|c|}{$\begin{array}{l}\text { Measles } \\
\text { associated }\end{array}$} & \multicolumn{2}{|c|}{ Blind* } & \multicolumn{2}{|c|}{ Mortality } \\
\hline & & $n$ & $\%$ & $n$ & $\%$ & $n$ & $\%$ & $n$ & $\%$ \\
\hline Vitamin A deficiency & 34 & 27 & 79 & 24 & 761 & 11 & 32 & 10 & 29 \\
\hline Herpes simplex & 47 & 11 & 23 & 10 & 21 & 1 & 2 & 3 & 6 \\
\hline $\begin{array}{l}\text { Traditional eye } \\
\text { medicines }\end{array}$ & 18 & 8 & 44 & 8 & 44 & 3 & 17 & 1 & 5 \\
\hline Other known causes & 21 & 3 & 14 & 0 & 0 & 1 & 5 & 0 & 0 \\
\hline $\begin{array}{l}\text { Measles confluent } \\
\text { keratitis }\end{array}$ & 5 & 0 & 0 & 5 & 100 & 0 & 0 & 0 & 0 \\
\hline Unknown & 5 & 0 & 0 & 1 & 20 & 0 & 0 & 0 & 0 \\
\hline Totals & 130 & 49 & $37 \cdot 74$ & & $36 \cdot 91$ & 16 & $12 \cdot 3$ & 14 & $10 \cdot 8$ \\
\hline
\end{tabular}

${ }^{*}$ Blind=binocular vision less than $3 / 60$.

contrast herpetic corneal ulceration followed measles in only $21 \%$ of cases, was bilateral in only $23 \%$ of cases, and was associated with significantly lower mortality (6\%) and blindness (2\%) (Table 6).

\section{Discussion}

MEASLES-ASSOCIATED CORNEAL ULCERATION Measles infection is usually accompanied by lacrimation, photophobia, and a keratoconjunctivitis which lasts for two to 10 days. Trantas ${ }^{25}$ and Dekkers ${ }^{11}$ have reported a superficial punctate keratitis due to measles virus which usually resolves as the skin rash fades, leaving no permanent sequelae. However, serious corneal complications following measles were documented in Europe in the last century and early part of this century, ${ }^{2627}$ but apart from very rare reports, ${ }^{28}$ blindness following measles-associated corneal ulceration has now disappeared from Europe.

In Africa, however, 1 to $4 \%$ of hospitalised children with acute measles develop true corneal ulceration as distinct from punctate keratitis. "1929-31 In this series $25 \%$ of unilateral and $57 \%$ of bilateral corneal ulcers occurred within one month of previous measles infection-findings similar to studies elsewhere. ${ }^{32}$ The ulceration was bilateral in $58 \%$ ( 28 of 48) of children developing corneal ulcers after measles, and 11 of these 28 children with bilateral measles-associated corneal ulcers were considered to have ulceration which would result in blindness despite hospital treatment. Measles was responsible for $69 \%$ of all children examined and judged to go blind from corneal scarring in this hospital based series. This figure is in general agreement with results from surveys carried out in blind schools in other African countries (33-79\%), ${ }^{8141833}$ confirming the importance of measles as a predisposing factor for corneal ulceration and blindness in African children. 
The mechanism by which measles causes corneal ulceration in Africa is controversial and complex. Herpes simplex corneal ulceration has been reported after measles." 181934 We deemed $21 \%$ of measlesassociated ulcers to be herpetic in origin, of which $30 \%$ ( 3 of 10 ) were bilateral. The ulceration was usually epithelial and occurred within two weeks of the measles rash in $80 \%$ of cases. There was no case of measles-associated herpetic ulceration which resulted in blindness, though superficial corneal scarring was a common sequela.

The use of TEM was responsible for $17 \%$ of measles-associated ulcers and for nearly one-fifth of the bilateral ulcers which resulted in children going blind. It seems probable that measles conjunctivitis causing red eyes, together with a local knowledge that measles and red eyes result in blindness, leads mothers to use TEM in an effort to help the child with measles. ${ }^{356} \mathrm{It}$ is possible that the children in whom TEM were used already had an underlying eye disease due to vitamin A deficiency or herpes simplex virus, but clinically these ulcers did not show the typical appearances of xerophthalmia or herpetic ulceration, nor did they respond to specific therapy.

Vitamin A deficiency was the commonest cause of measles associated ulceration (50\%) and of subsequent bilateral blindness. Early signs of xerophthalmia - night blindness and Bitot's spots-were uncommon, occurring in only five of 24 children with measles-associated ulcers due to vitamin A deficiency. Sommer ${ }^{37} 38$ suggests that this absence of early clinical signs of vitamin A deficiency in measles may be due to the accompanying inflammation which causes the conjunctival xerosis and Bitot's spots to disappear, or possibly measles causes a sudden decompensation in vitamin A metabolism in children who are asymptomatic but have depleted stores of vitamin $\mathrm{A}$ in the liver. The reduced dietary intake, ${ }^{39}$ malabsorption, ${ }^{40}$ and increased demands ${ }^{41}$ for protein and vitamin $A$ which occur in measles may result in a sudden fall in available vitamin $A$ to the tissues and consequent corneal ulceration. The evidence for vitamin A deficiency being the cause of these ulcers was based on the clinical appearance of the ulcer (Table 3) and the dramatic response to therapy (as in case 3). Vitamin A biochemistry was available on 41 of the 130 children, and was in agreement with the clinical diagnosis in the great majority of cases (Fig. 16). Measles is known to have a depressive effect on vitamin A levels. ${ }^{3}$ However, there was a statistical difference in vitamin A levels between the children with measles-associated, clinically diagnosed, xerophthalmic ulcers, and age/sex measles matched controls without ulcers.

Of children with measles-associated corneal ulcers $11 \%$ developed a round, epithelial, usually central ulcer, which occurred within 10 days of the measles rash appearing. In some children this ulceration was seen to develop from the more typical measles superficial punctate keratitis (case 5). These epithelial ulcers healed quickly when treated with antibiotics and patching of the eye. This type of ulcer is probably due to a confluent form of measles keratitis accentuated by desiccation of the cornea due to exposure. Dekker described this appearance in $4 \%$ of children with typical measles SPK, and demonstrated the presence of measles virus in corneal scrapings. ${ }^{10}$ Our experience suggests that this type of measles-associated epithelial corneal ulceration has a good prognosis and does not usually lead to severe ulceration and blindness.

We therefore suggest that there are four main pathways by which measles may cause corneal ulceration: (1) sudden decompensation of subclinical vitamin A deficiency; (2) the use of traditional eye medicines; (3) infection with herpes simplex virus; (4) confluent measles keratitis with or without exposure.

Ulceration due to vitamin A deficiency or TEM often results in bilateral severe corneal destruction with a high rate of blindness. It may be very difficult clinically to know how much of the ulceration is due to the vitamin A deficiency and how much has been caused by TEM, and both causes may be significant factors in the same individual. Confluent measles keratitis or secondary infection with herpes simplex virus is more likely to be unilateral and usually involves only the epithelium and anterior corneal stroma, with complete healing or superficial corneal scarring being the usual outcome.

The relative importance of each individual cause of measles-associated ulceration in different parts of Africa will depend on (1) the prevalence of vitamin A deficiency and undernutrition in the childhood population, (2) local practices in relation to measles infection-for example, the use of TEM, or the withholding of food and water ${ }^{35}$ - and (3) the prevalence of herpes simplex virus infection in children and their mothers. These factors will vary in time and place according to the availability of food and seasonal variations in infectious diseases.

\section{HERPES SIMPLEX}

Corneal ulceration due to HSV has been previously documented from African countries. ${ }^{11} 18 \%+2$ In this study $36 \%$ of all childhood ulcers and $45 \%$ (37 of 82 ) of non-measles ulcers were herpetic in origin.

It has been suggested that children with malnutrition or measles are more susceptible to herpes simplex infection because of suppression in cellmediated immunity. ${ }^{42-44}$ This may explain some of the corneal ulcers seen in this series in severely under- 
nourished children (cases 6 and 7) and measles (case 9 ). However, ulceration did occur in apparently well nourished children in the absence of measles. In this group it was often noted that the child was suffering or recovering from malaria, and that childhood admissions with herpetic ulceration peaked each year during the malaria season. One possible explanation is that the fever associated with malaria (or measles) may cause shedding of the $\mathrm{HSV}^{45}$ and subsequent herpetic keratitis.

$51 \%$ of the herpetic ulcers showed a geographic or amoeboid pattern, $23 \%$ were bilateral, and $51 \%$ occurred in children under the age of 2 years. All these characteristics are atypical for 'Western' herpetic ulceration and are usually associated with herpetic infection in patients with depressed cellmediated immunity. Herpes simplex virus may cause pneumonitis ${ }^{46}$ and disseminated infection ${ }^{44}$ leading to death. Three out of 47 children $(6.4 \%)$ with herpetic ulcers died in this series. One child died during the first week of measles infection, and the other two were severely malnourished twins (cases 6 and 7), who may have died of disseminated herpetic disease.

Children with herpetic corneal ulceration were intensively treated with idoxuridine ointment or drops, and the ulceration usually healed in seven to 14 days, leaving residual superficial scarring and vascularisation. Two children returned with a recurrence in the same eye and one child with a new herpetic ulcer in the other eye during the study period. Only one child was judged to become blind in both eyes due to herpetic infection, though most were left with superficial corneal scarring, a reduction in visual acuity, and the possibility of recurrent disease later in life..$^{47}$

It would appear that HSV is a common cause of corneal ulceration in children, being associated with measles, malaria, and malnutrition, but because of its unusual and late presentation it may often go undiagnosed. It may occasionally be associated with disseminated herpes infection and death. Blindness is, however, uncommon, though some visual loss from corneal scarring and recurrent disease in later life seem likely.

\section{VITAMIN A DEFICIENCY}

Vitamin A deficiency was found to be the most important cause of bilateral ulceration (27 of 49), measles-associated ulceration (24 of 48), and resultant bilateral blindness (11 of 16). The clinical appearances varied from small, punched out, round or oval ulcers involving the corneal stroma to complete necrosis of the cornea. The more severe the corneal lesion the more likely it was to be bilateral, and the child was more likely to die (Table 4 ). The response to therapy in early cases is dramatic, with healing of the ulcer and scar formation within four to five days of oral vitamin A administration (case 3). However, in late cases, where there is limbus-to-limbus corneal necrosis, it is impossible to salvage the eye despite vitamin A therapy (case 2). Clinically many of the children with vitamin A deficiency were noted to have dry eyes, dry mouth, a high pitched croupy cough, and to develop respiratory infections. The high mortality $(29 \%)$ in children with ulceration due to vitamin A deficiency is similar to findings elsewhere. ${ }^{3}$

Because of the high mortality and high rate of blindness associated with vitamin A deficiency, and because treatment is simple and inexpensive, the prevention, early diagnosis, and treatment of vitamin A deficiency must be a priority in any area where protein-energy malnutrition or childhood blindness due to corneal scarring from measles is a problem.

\section{TRADITIONAL EYE MEDICINES}

The diagnosis of corneal ulceration due to TEM is based upon a history of using TEM-which the mothers are usually reluctant to confess to- together with the appearances of chemical conjunctivitis and irregular atypical corneal ulcers (case 4). These ulcers do not respond to therapy with vitamin A or antivirals, and usually take three to four weeks to settle on antibiotics, with resultant dense corneal scarring. There is nearly always an underlying eye disease which has caused the mother to use the traditional medicines. This may be measles keratoconjunctivitis, bacterial conjunctivitis, herpes simplex keratitis, xerophthalmia, or any other eye disease. In this series two cases followed the use of TEM in the eye for cutaneous anthrax of the eyelid. It is often difficult to decide whether the TEM or underlying eye disease are most responsible for the corneal ulceration.

Very little is known about the substances used in preparing these medicines, though plants and human or animal urine are often included. ${ }^{35}$ The ulceration may be caused by a caustic effect on the cornea from plant extracts, or possibly by secondary infection with bacteria (including Neisseria gonorrhoeae) or fungi after the epithelium has been damaged.

Because of the difficulties in obtaining a positive history, and the variety of clinical appearances, the diagnosis of ulceration due to TEM is probably underestimated. The consequences of using TEM may be drastic, with nearly half of the ulcers being bilateral and a significant number resulting in blindness in both eyes.

\section{OTHER CAUSES OF CORNEAL ULCERATION}

Other known causes of corneal ulceration in childhood included ophthalmia neonatorum, trauma, 
bacterial infection, corneal exposure due to proptosis, and trachoma. None of these were related to measles infection, and only those cases due to ophthalmia neonatorum were bilateral, one of which patients became blind. There was no case of fungal keratitis.

\section{CONCLUSION}

Many factors are involved and interact in producing corneal ulceration in African children. They include measles infection, the use of traditional eye medicines, herpes simplex infection, and vitamin A deficiency. The frequency of herpetic ulceration in young children has probably been underestimated, in part owing to the atypical clinical presentation. The importance of the use of TEM is likely to vary from one place to another and is difficult to define because of its interaction with other eye diseases.

Measles infection appears to be the major precipitating factor which puts the African child at risk of developing corneal ulceration and becoming blind, while vitamin A deficiency was the most important cause of bilateral ulceration and resultant blindness in this study, and was also associated with a very high mortality.

Measles vaccination programmes and the provision of an adequate intake of vitamin $A$ in the diet of preschool children, though logistically difficult to accomplish, must remain the first priorities in the prevention of childhood blindness in Africa.

The prophylactic use of one vitamin A capsule (200000 IU) to all children with measles or undernutrition (less than $80 \%$ weight for age) would seem to be a reasonable short-term medical intervention, while nutrition education programmes aimed at increasing the dietary vitamin A for preschool children are developed.

The majority of childhood corneal ulcers in many African countries will present initially to a primary health worker or medical auxiliary. In this situation it is recommended that all children with corneal ulcers be given 200000 IU of vitamin A orally (immediately and 24 hours later) and intensive antibiotics (hourly eye drops or eye ointment at least four times a day). Steroids in any form must not be used, and should not be available to the general medical auxiliary. It is unlikely that antivirals will be available in rural situations, but mechanical debridement of herpetic ulcers in children should be considered only by those experienced and well trained in the diagnosis and management of herpetic keratitis.

These investigations were supported in part by the Ministry of Health, Government of United Republic of Tanzania; Cooperative Agreement Number AID/DSCN 0267 between the Office of Nutrition, United States Agency for International Development, and the International Centre for Epidemiologic and Preventive
Ophthalmology, Johns Hopkins University; the World Health Organisation's Prevention of Blindness Programme; and Christoffel Blindenmission, West Germany.

\section{References}

1 International Agency for Prevention of Blindness. Sir John Wilson, world blindness and its prevention. Oxford: University Press, 1980.

2 Sommer A. Field guide to the detection and control of xerophthalmia, Geneva: WHO, 1978.

3 Sommer A. Nutritional blindness. New York: Oxford University Press, 1982.

4 Shah PM. Strategies for prevention of malnutritional blindness in India, operational methodology, management, monitoring and cost-benefit. Royal Commonwealth Society for the Blind, 1978.

5 Gopalan C, Vijayaraghavan K. Nutritional atlas of India. New Delhi: Indian Council of Medical Research, 1971: 67, 159.

6 Reddy V. Vitamin A deficiency and blindness in Indian children. Indian J Med Res 1978; 67: (suppl) 26-37.

7 Franken S. Blindness prevention programme in Bangladesh. Assignment Report. WHO/SEA Ophthalmology 1975: 4.

8 Chirambo MC, BenEzra D. Causes of blindness among students in blind school institutions in a developing country. $\mathrm{Br} \mathrm{J}$ Ophthalmol 1976; 60: 665-8.

9 Sauter JJ. Causes of blindness detected in 19 schools for blind in Tanzania. Final Report for Ministry of Health, 1978. Dar-esSalaam, 1978.

10 Sandford-Smith JH, Whittle HC, Corneal ulceration following measles in Nigerian children, $\mathrm{Br} J$ Ophthalmol 1979; 63: 720-4.

11 Dekkers NWHM. The cornea in measles. The Hague: Junk, 1981.

12 Thomson IG. Eye diseases and blindness in relation to vitamin A deficiency in northern Nigeria. J Trop Med Hyg 1956; 59: 115-61.

13 McLaren DS, Nutrition and eye disease in East Africa: experiences in Lake and Central Provinces, Tanganyika. J Trop Med Hyg 1960: 63: 101-22.

14 Awdry PN, Cobb B, Adams PCG. Blindness in the Luapula Valley. Centr Afr J Med 1967; 13: 197-201.

15 Cobb B, Awdry PN. Xerophthalmia. Trans Ophthalmol Soc UK 1968; 88: 579-85.

16 Franken S, Measles and xerophthalmia in East Africa. Trop Geogr Med 1974; 26: 39-44.

17 Oomen JMV. Xerophthalmia in Northern Nigeria. Trop Geogr Med 1971; 23: 246-9.

18 Sauter JJ. Xerophthalmia and measles in Kenya. Groningen: Van Denderen, 1976.

19 Whittle HC, Sandford-Smith J, Kogbe OI, Dosseter J, Duggan $M$. Severe ulcerative herpes of the mouth and cye following measles. Trans R Soc Trop Med Hyg 1979; 73: 66-9.

20 Philips CM. Blindness in Africans in Northern Rhodesia. Cent Afr J Med 1961; 7: 153-8.

21 MacManus EP. Xerophthalmia in Matcbelcland. Cent Afr J Med $1968 ; 14: 166-70$

22 Morley D. Severe measles in the tropics. Part 1. Br Med J 1969; i: 297-300.

23 Tarizzo ML. Field guide for the control of trachoma. Geneva: WHO, 1973.

24 O'Day DM, Jones BR. Herpes simplex keratitis. In: Duane TE. Clinical ophthalmology. Hagerstown: Harper and Row, 1980): 4: chapter 19.

25 Trantas M. Complications oculaires rares de la rougćolc. Ann Oculist (Paris) 1900; 123: 300.

26 MacKenzie W. A practical treatise on diseases of the eye. London: Longman, 1830: 88-199.

27 Bloch CE. Clinical investigation of xerophthalmia and dysentery in infants and young children. J Hyg (Lond) $1921 ; 19: 283-301$.

28 Blatz G. Hornhauteinschmelzung nach Mascrn. Klin Monatsbl Augenheilkd 1956; 129: 763-72. 
29 Foster A. Focus on blindness in Africa. In: Foster A, ed. Proceedings of the sub-regional seminar on prevention of blindness. New York: Helen Keller Institute, 1984: 16.

30 Gupta BM, Singh M. Mortality and morbidity pattern in measles in Tanga district, Tanzania. Trop Geogr Med 1975; 27: 383-6.

31 Leary PM. The pattern of measles among Africans in a Bantu reserve. $S$ Afr Med J 1966; 40: 293-5.

32 Foster A, Sommer A, Kavishe F. Taylor HR. A surveillance system for xerophthalmia and childhood corneal ulceration. Bull WHO in press.

33 Animashaun A. Measles and blindness in Nigerian children. Niger J Paediatr 1977; 4: 10.

34 Sachs U, Marcus M. Bilateral herpetic keratitis during measles. Am J Ophthalmol 1981; 91: 796-7.

35 Imperato PJ. Traditional attitudes towards measles in the Republic of Mali. Trans $R$ Soc Trop Med Hyg 1969; 63: $768-80$.

36 Morley D, Allen I, Martin WJ. Preliminary Results of a worldwide enquiry into beliefs associated with measles. London: Institute of Child Health, 1966.

37 Sommer A, Muhilhal. Nutritional factors in corneal xerophthalmia and keratomalacia. Arch Ophthalmol 1982; 100: 399-403.

38 Sommer A. Conjunctival appearance in corneal xerophthalmia. Arch Ophthalmol 1982; 100: 951-2.
39 Morley DC. Measles and measles vaccine in pre-industrial countries. Mod Trends Med Virol 1967; 1: 141-61.

40) Dosseter J, Whittle HC. Protein losing enteropathy and malabsorption in acute mealses enteritis. Br Med J 1975; ii: 592-3.

41 Garlick P. McNurlan M. Fern E. Tomkins A, Waterlow JC. Protein synthesis and breakdown after vaccination. $\mathrm{Br}$ Med $J$ 1980; 281: 1215-6.

42 Kuming BS, Politzer W. Xerophthalmia and protein malnutrition in Bantu children. Br J Ophthalmol 1967; 51: 649-66.

43 Templeton AC. Generalised herpes simplex in malnourished children. J Clin Pathol 1970; 23: 24-30.

44 Kaufmann H. Update on anti-viral agents. Ophthalmology (Rochester) 1985; 92: 533-6.

45 Kipps A. Kaschula ROC. Virus pneumonia following measles. A virological and histological study of autopsy material. $S$ Afr Med J 1976; 50: 1083-8.

46 Kipps A, Becker W, Wainwright J, MacKenzic D. Fatal disseminated primary herpes virus infection in children: epidemiology based on 93 non-neonatal cases. S Afr Med J 1967: 41: $647-51$.

47 Wilhelmus KR, Falcon MG, Jones BR. Bilateral herpetic keratitis. BrJ Ophthalmol 1981; 65: 385-7.

Accepted for publication 8 July 1986. 